Technological University Dublin

DÜBLIN

ARROW@TU Dublin

\title{
An examination of the role of spatial ability in the process of problem solving in chemical engineering
}

\author{
Sheryl Sorby \\ University of Cincinnati, sheryl.sorby@uc.edu \\ Gavin Duffy \\ Technological University Dublin, gavin.duffy@tudublin.ie \\ Norman Loney \\ University of Cincinnati
}

Follow this and additional works at: https://arrow.tudublin.ie/engineducart

Part of the Engineering Education Commons, and the Higher Education Commons

\section{Recommended Citation}

Sheryl A. Sorby , Gavin Duffy \& Norman Loney (2020): An examination of the role of spatial ability in the process of problem solving in chemical engineering, Australasian Journal of Engineering Education, DOI: $10.1080 / 22054952.2020 .1785653$

This Article is brought to you for free and open access by the Engineering: Education and Innovation at ARROW@TU Dublin. It has been accepted for inclusion in Articles by an authorized administrator of ARROW@TU

Dublin. For more information, please contact

arrow.admin@tudublin.ie, aisling.coyne@tudublin.ie, gerard.connolly@tudublin.ie.

Funder: National Science Foundation

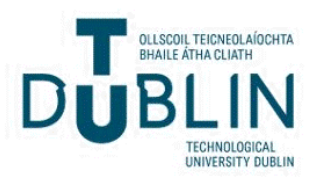




\section{Australasian Journal of Engineering Education}

\section{An examination of the role of spatial ability in the process of problem solving in chemical engineering}

\section{Sheryl A. Sorby , Gavin Duffy \& Norman Loney}

To cite this article: Sheryl A. Sorby , Gavin Duffy \& Norman Loney (2020): An examination of the role of spatial ability in the process of problem solving in chemical engineering, Australasian Journal of Engineering Education, DOI: 10.1080/22054952.2020.1785653

To link to this article: https://doi.org/10.1080/22054952.2020.1785653

曲 Published online: 28 Jul 2020.

Submit your article to this journal $₫$

Q View related articles ¿

View Crossmark data $\nearrow$ 


\title{
An examination of the role of spatial ability in the process of problem solving in chemical engineering
}

\author{
Sheryl A. Sorby ${ }^{\mathrm{a}}$, Gavin Duffy ${ }^{\mathrm{b}}$ and Norman Loney ${ }^{\mathrm{c}}$ \\ aDepartment of Engineering Education, University of Cincinnati, Cincinnati, Ohio, USA; 'bepartment of Electrical Engineering, \\ Technological University Dublin, Dublin, Ireland; 'Department of Chemical and Environmental Engineering, University of Cincinnati, \\ Cincinnati, Ohio, USA
}

\begin{abstract}
Engineers often communicate with one another through drawings or sketches and understanding technical information through graphical representations is a skill necessary for engineering practice. Well-developed spatial skills are known to be important to understanding technical drawings and are therefore, important to success in engineering. Unfortunately, of all cognitive processes, spatial skills show robust gender differences, favouring males, which could contribute to the underrepresentation of women in engineering. In this research, we administered a test of spatial cognition to students enrolled in a common 3rd year course in chemical engineering. In a second session, students were given a set of 12 textbook problems from a prerequisite course to solve, to determine if there was a link between scores on a spatial instrument and the number and type of problems solved correctly. Both instruments were scored and statistical analyses were performed. A strong positive correlation $(r=0.59$, $p<0.00001$ ) between spatial skills test scores and the number of problems successfully solved by the students was found, confirming the link between spatial skills and engineering problemsolving. This paper describes the findings from this research, including identification of the type of problems where spatial skills appear to play a role.
\end{abstract}

ARTICLE HISTORY

Received 25 January 2020

Accepted 3 May 2020

\section{KEYWORDS}

Spatial ability; problem

solving; engineering

education; gender

differences

\section{Introduction}

Problem solving is a core attribute of engineering practice. The etymology of engineer can be traced to 'ingeniare', which translates as inventor or designer, roles whose purpose is to solve problems. Professional bodies expect engineering education programmes to develop problem solving skills (e.g., ABET 2016) and often refer to a spectrum of problem type ranging from ill- to well-structured. It is important for engineering educators to understand not just the problemsolving process but how students can vary in their approaches to problem solving and the underlying reasons for such variation. By definition, problems are cognitive tasks that are novel and have not been practiced or seen before. At a cognitive level, problem solving typically draws on a combination of learned knowledge and in-the-moment thinking. To develop an understanding of the problem solving process in the context of engineering education, one can learn from the literature on cognitive psychology which has tried to describe thinking as the interplay between a suite of cognitive factors (e.g., Schneider and McGrew 2012) or in terms of the types of memory long term and working memory - that are brought to bear on these tasks (e.g., Baddeley and Logie 1999).

Spatial ability occupies a prominent role in a wide range of well-established theories and models of intelligence (Carroll 1996; Johnson and Bouchard 2005; Lohman 1996; Schneider and McGrew 2012). It is a key cognitive attribute relevant to thinking across a range of activities including navigation, spatial visualisation and problem solving. It is strongly associated with success in STEM (Science, Technology, Engineering, Mathematics) learning (Wai, Lubinski, and Benbow 2009) because many STEM topics require the ability to visualise images, mentally manipulate them and transform them in different ways. Einstein and others who have created the ideas and models that comprise STEM knowledge were highly visual thinkers (Lohman 1996). Indeed, Einstein provided many descriptions of how he visualised objects falling through space from two different frames of reference when formulating theories of relativity (Isaacson 2007). Spatial ability is therefore a core aspect of human intelligence that is critical to the process of learning STEM which requires the mental representation of novel tasks and problems.

Spatial ability has been defined in different ways depending on the interpretation of results from factor analysis of psychometric data but the following factors consistently emerge: mental rotation, the ability to visualise a well-structured image and mentally rotate it to a new orientation, spatial visualisation, the ability to discern, analyse and manipulate complex spatial

CONTACT Sheryl A. Sorby Sheryl.sorby@uc.edu O University of Cincinnati, 2851 Woodside Drive, ML0074, Cincinnati, OH 45221, USA 
patterns and spatial orientation, the ability to perceive objects in space and visualise how they, and/or you as the observer, are repositioned relative to each other from different perspectives (Mix and Cheng 2012). It is common in studies of spatial ability in STEM to use tests that measure the first two factors, mental rotation and spatial visualisation. For example, in their analysis of Project Talent data, Wai, Lubinski, and Benbow (2009) created a composite score for spatial ability that consisted of both factors and also included mechanical reasoning. In studying the relationship between spatial ability and reasoning about force and motion in Newtonian mechanics, Kozhevnikov et al. (Kozhevnikov, Hegarty, and Mayer 2002) have used tests of both spatial visualisation and mental rotation and found them to load on the same factor as performance on the physics problems. As a result, in a subsequent study of the same topic, a composite spatial ability score was based on averaging results from spatial visualisation and mental rotation tests. Since engineering students tend to have high levels of spatial ability (they were ranked highest in spatial ability of all higher education disciplines included by Wai, Lubinski, and Benbow 2009), spatial tests must be challenging for ceiling effects to be avoided. Both the Purdue Spatial visualisation Test: Rotations (PSVT:R, Guay 1976), a test of mental rotation, and the Mental Cutting Test (MCT, CEEB 1939), a test of spatial visualisation, have been shown to be popular ways to measure spatial ability of STEM students (Yoon 2011).

Another description of how we think, particularly during novel tasks such as problem solving, is provided by memory models of cognition which distinguish between long term, short term and working memory (Baddeley 2012). Although different tests that measure memory span are used within this paradigm, tests of spatial visualisation have also been used to measure visuospatial working memory (Kyttälä and Lehto 2008). Since the MCT requires both the storage and processing of spatial information, it is a working memory task. As the topic investigated in this study is problem solving, spatial visualisation was chosen as it provides an assessment of both visuospatial working memory and a factor of spatial ability that is important to STEM tasks. In previous research conducted examining the link between spatial thinking and success in problem-solving (Duffy, Sorby, and Bowe 2020), it was determined that spatial ability appears to play a significant role in the problem conception stage, particularly for word problems. High levels of spatial ability enabled students to translate words into equations that could subsequently be solved.

\subsection{Spatial ability and gender}

For more than 100 years, scientists have found significant gender differences in 3D spatial skills, favouring males (e.g., Linn and Petersen 1985; Voyer, Voyer, and Bryden 1995; Sorby et al. 2013; Duffy et al. 2017). More recent studies have found that sex differences in spatial skills persist (Ganley and Vasilyeva 2011; Tarampi, Heydari, and Hegarty 2016; Sorby et al. 2013). Geiser, Lehmann, and Eid (2008) found that sex differences existed at all ages between 9 and 23, and that differences increased with age. In an examination of 14 years of data, Veurink and Sorby (2011) found significant gender differences among engineering students for each year. Although it appeared that the gender gap was narrowing slightly over that time period, the gap was never eliminated altogether.

There is no universal agreement regarding why gender differences in spatial skills exist. Some researchers hypothesise that the difference is biological (e.g., Heir and Crowley 1982) or evolutionary (Silverman et al. 2000). Others believe that environmental factors contribute to lower spatial skills for women/girls. Research shows that one reason females tend to have relatively low spatial skills compared to their male peers could be related to the type of toys they played with and activities they engaged in while growing up. Students with high spatial ability at the university level tended to play with Legos, take shop or mechanics classes, fix and put together things like bicycles, or play certain shoot 'em-up computer games during their middle and high school years (Deno 1995; Sorby and Veurink 2012; Sorby, Leopold, and Gorska 1999). In research conducted by Casey, Pezaris, and Nuttall (1992), they examined the nature versus nurture debate in terms of spatial skills development and found that there is likely an interaction between biological and environmental factors in the development of spatial skills for women. Eliot (2009) has examined neurological brain structure in both boys and girls and believes that for spatial reasoning, we start with a small gender difference in brain structure that grows larger as a child develops and engages with toys and activities that either support the development of spatial skills or do not support this development. Regardless of the reason for the gender differences in spatial skills, the fact remains that spatial skills are important to success in engineering and that relatively weak spatial skills for females could hinder our ability to diversify the profession. The good news is that spatial skills can be developed and learned through practice (Uttal 2013).

Sorby and colleagues have developed a curriculum for a 1-credit course designed to help first-year engineering students, particularly women, improve their 3-D spatial skills (Sorby 2016). Implementation of the course has led to improved grades in introductory STEM courses and to increased retention and graduation rates for engineering students, particularly for women (Sorby, Veurink, and Streiner 2018). The course has been adopted by a number of colleges of 
engineering in the United States; however, not every programme is willing to implement an extra course aimed at improving spatial skills. Understanding the importance of spatial thinking in problem-solving could mean that engineering programmes restructure their courses to include better support for students in the problem conception stage, since this appears to be where spatial skill levels likely play a role.

\subsection{Spatial ability and mathematics}

Clement (1982) highlighted how apparently simple word algebra problems can be extremely difficult for engineering students to solve. For example, the success rate on the following problem was only $27 \%$ :

\footnotetext{
"Write an equation using the variables $\mathrm{C}$ and $\mathrm{S}$ to represent the following statement:
}

At Mindy's restaurant, for every four people who ordered cheesecake, there are five people who ordered strudel.

Let $C$ represent the number of cheesecakes and $S$ the number of strudels." (Clement 1982, 17)

Why did over two thirds of the 150 first-year engineering students fail to correctly translate this word statement? Carelessness was considered but Clement ruled this out because he found that a large cohort, approximately two thirds of the incorrect group, provided the same (incorrect) answer. He believed this reflected focused, careful thinking about the problem but a thinking that resulted in a different translation of the word statement. Where the answer should have been $5 \mathrm{C}=4 \mathrm{~S}$, about half the participants wrote $4 \mathrm{C}=5 \mathrm{~S}$ a result of what Clement labelled as 'word order matching'. Even when the underlying mathematics is very simple, engineering students can have great difficulty in solving word problems despite careful thinking and analysis. The authors believe that one possible explanation for these differences lies in differences in spatial skills of the student participants.

It has been shown that spatial and mathematical abilities are strongly associated with each other and that the magnitude of variation shared between tests of spatial and mathematical abilities varies not only with task type but also across development stage from early childhood through adolescence and into adulthood (Mix and Cheng 2012). There is evidence that spatial visualisation skill predicts course selection and success in physics (Kozhevnikov, Motes, and Hegarty 2007), chemistry (Wu and Shah 2004), engineering (Sorby 2001) and geology (Kali and Orion 1996).

At a large Midwestern university in the U. S., all incoming first-year engineering students are required to take a maths placement test (MPT) and the Purdue Spatial visualisation Test: Rotations (PSVT:R, Guay
1976). The MPT contains 25 questions with multiple choice answers; only one question is presented in the form of a word problem. While a small significant correlation was measured between the two tests ( $r$ $(1051)=.21, \mathrm{p}<.01)$ the word problem revealed the largest effect size with spatial ability (Duffy et al. 2017). In another study, several word problems in mathematics were administered to first year engineering students in Ireland and the US and a significant correlation was found with performance on the PSVT:R $(\mathrm{r}(113)=.544, \mathrm{p}<.001)($ Duffy, Sorby, and Bowe 2020). Hence, among engineering students there is evidence to suggest a strong relationship between spatial ability and word problem solving in mathematics.

In a study of the relationship between spatial ability and problem solving among first year engineering students, it was found that spatial ability was significantly and highly related to success in representation but not related to the mathematical abilities required in the solution phase (Duffy, Sorby, and Bowe 2020). Students with low spatial ability were much more likely to make errors in translating assignment and relational statements and in selecting an appropriate schema for the problem but there was no difference in the mathematical ability (required for the problems) between the low and high spatial ability students.

The role of visualisation in problem solving was also examined in studies of $6^{\text {th }}$ grade school children in which they were presented with a series of word problems and both quality and accuracy of their visualisations were judged either by looking at sketches they produced or by asking them if no sketches were produced (Boonen et al. 2014; Hegarty and Kozhevnikov 1999). In this study, there was a strong association between spatial ability and the creation of accurate and schematically appropriate visualisations. Low spatial ability students were more likely to produce 'pictorial' visualisations, i.e. a picture that represented the context of the problem but did not contain any of the assignment and relational statements or any schematic details.

Factorial models of intelligence tend to limit the role of spatial ability to tasks associated with the generation and manipulation of visualisations from wellstructured images (e.g., Carroll 1993; Linn and Petersen 1985; McGee 1979). However, word problems that do not contain well-structured images also require spatial ability in order to be represented even when visualisation is not necessarily apparent. Thinking about problem scenarios is cognitively challenging and those with a particular cognitive ability profile in which spatial ability is augmented are well suited to such challenges. In order to better prepare the next generation of engineers we should seek ways to transfer research on spatial cognition into practice to provide students with opportunities to develop not 
just verbal and mathematical abilities but their spatial abilities too. We believe this will transfer to enhanced performance in a wide range of tasks that not only require visualisation but also require thinking through non-routine problems and forming mental representations from ambiguous problem statements.

\section{Research questions}

Studies have shown the link between well-developed 3-D spatial skills and success in engineering overall. One particular area where spatial visualisation skills are hypothesised to be advantageous is in problem solving. Tversky (2005) posits that possessing advanced spatial abilities allows an individual to construct robust mental representations of problems. The following research questions guided this study:

(1) Is there a link between spatial skills and problem-solving in chemical engineering?

a. If there is a link between the two, what type of problem appears to rely on spatial thinking to a greater extent than other types?

(2) Are there gender differences in the spatial skills of students enrolled in a chemical engineering program similar to those reported elsewhere?

We hypothesise that there is a link between spatial skills and problem-solving, but not for all types of problems. We further hypothesise that there will be gender differences in the spatial skills for our student subjects.

\section{Methods and materials}

Students enrolled in a Thermodynamics course at the University of Cincinnati were administered a test of spatial visualisation, the Mental Cutting Test (MCT, CEEB 1939) and a set of problems. While it is known that tests of mental rotation such as the PSVT:R are related to problem solving, the MCT is also a suitable test to use because it assesses the same factor of spatial ability, spatial visualisation (Carroll 1993). According to a typology of spatial tests, both the MCT and the PSVT:R are classified in the same way: they are intrinsic dynamic tests, i.e. the information to be visualised is intrinsic to the object in view and the object is transformed in a dynamic way. Previous studies have shown high correlations between the MCT and the PSVT:R (e.g., Farrell et al. 2015). A sample problem from the MCT is shown in Figure 1. The MCT is a timed test (20 minutes) with 25 total items. Scores are computed as the total number of correct answers out of 25 ; no points are subtracted for incorrect responses.

The Thermodynamics course is typically taken during a student's third year of study. The course where they learn about mass-balance is a prerequisite to

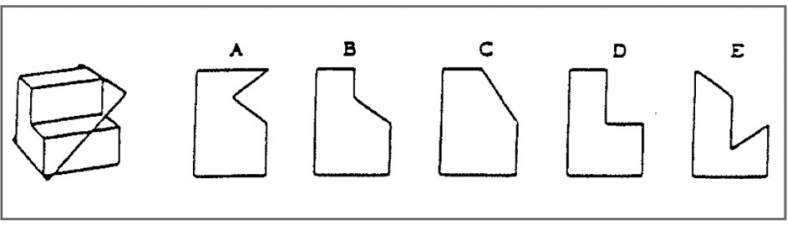

Figure 1. Sample problem from the MCT (Correct answer is D).

Thermodynamics. Most of the set of problems developed for this study was taken from problems used in previous studies and from a commonly used introductory textbook for this topic (Felder and Rousseau 2000). The problem set consisted of 12 problems, 8 of which were mass-balance and 4 were mass-balance with stoichiometry. These types of problems were selected as they are fundamental to, and considered to be, core competencies in this discipline of engineering, and it was expected that third year students would have these competencies and the procedural knowledge required to solve this type of problem. The subject content contained in these problems is not advanced and is covered in second year in a chemical engineering program. The mathematical procedural knowledge required to solve these problems consists of basic algebra and arithmetic, maths skills that engineering students developed in high school. An important factor in selecting these problems is they are phrased in a context through words and require the problem solver to form a representation of the problem, a cognitive challenge that has been shown to overlap with spatial ability in other subject areas (Duffy et al., 2020). In other words, these problems were chosen because (i) they are chemical engineering problems, (ii) the procedural knowledge required for the solution phase is basic to chemical engineering students in their third year of study and (iii) the problem solver must form a mental representation of the problem from the information contained in the word problems. The MCT was administered to the sample during one class period and the problem set was administered in another class period. Participants were asked to solve as many problems as they could in the time available. Prior to collecting data, participants were informed about the study and only students' data from those who consented to participate in the study are included in this paper.

\section{Results}

Average scores on the MCT were computed and disaggregated by gender. Table 1 includes the results from this analysis.

Contrary to our hypothesis, gender differences on average MCT scores were not statistically significant at the $\mathrm{p}=0.05$ level; however, there was a smallmedium effect size. It should be noted that in previous testing conducted with first-year students, 
Table 1. Average scores on the MCT disaggregated by gender.

\begin{tabular}{lccc}
\hline & & $\begin{array}{c}\text { Average MCT score } \\
\text { (std deviation) }\end{array}$ \\
Group & Sample Size & [Confidence Interval] & Significance \\
\hline Males & 43 & $48.5 \%$ & $\mathrm{p}=0.0910 ;$ \\
& & $(18.3 \%)$ & Cohen's $d=0.46$ \\
Females & 20 & {$[43.03,53.97]$} & \\
& & $39.8 \%$ & \\
& & $(19.6 \%)$ & \\
& & {$[31.21,48.39]$} & \\
\hline
\end{tabular}

significant gender differences on tests of spatial cognition are typically observed (e.g., Sorby et al. 2013). The fact that no significant gender differences were found in this study could be indicative of either a) women with weak spatial skills left the chemical engineering programme prior to enrolling in their third year courses or b) women developed their spatial skills over the course of their three years in the chemical engineering programme, closing the gender gap somewhat, or c) a combination of both a and b. Unfortunately, data for first year students regarding spatial skill levels were not available for this student sample, meaning that it is impossible to definitively state which of these theories is correct. However, in previous research conducted by Sorby (2001), the retention rate of women engineering students who began with initially weak spatial skills was $47 \%$ compared to $77 \%$ for women who had initially weak spatial skills but who participated in the spatial skills intervention course. In another study (Sorby, Veurink, and Streiner, 2018), it was found that women were twice as likely to be retained in engineering if they had participated in the intervention compared to those who did not. Thus, it seems probable that women with weak spatial skills would be more likely to leave engineering compared to those with strong skills (the current study was conducted at a university where the spatial skills intervention course is not available). Further, in other research conducted by Veurink and Sorby (2014), it was found that, on average, spatial skills for Chemical Engineering students improved from $77.7 \%$ to 95.7\% on a test of spatial cognition between their first and fourth years. The data analysed in this study were paired, meaning that the spatial skills of the students improved as a result of their enrolment in the chemical engineering program. Based on these previous studies, there is evidence to support either of these theories.

Another reason for a lack of statistical significance in gender difference could be the relatively low sample size. Yet another factor could be the relatively high standard deviations for the samples, meaning that the student scores on the MCT exhibited a great deal of variability.

Since the students were all given the same amount of time, those who were better at problem-solving would likely solve a larger number of problems correctly compared to weaker students. Figure 2 shows the correlation between the number of problems correctly solved and scores on the MCT. A strong positive correlation $(\mathrm{R}=0.55, \mathrm{p}<0.00001)$ between spatial skills test scores and the number of problems successfully solved by the students was found.

In addition, we examined the scores by attempts. If a problem was not attempted, it could mean that either a) they didn't know how to do the problem, or b) they ran out of time. Not all students answered all questions nor did they answer them sequentially. In fact, it appeared that some students only attempted the problems that they thought they could solve. For example one student solved problems 1, 2, 3, 4, 5, 8 and 10 getting six of the seven attempted problems correct. If we express student scores in terms of the percent correct $(85.7 \%$ for the example student), we obtain the scatter plot shown in Figure 3. Note that for this analysis, the positive correlation is still present but it is not as strong as the correlation obtained just by looking at correct answers ( $\mathrm{R}=0.55$ correct answers only; $\mathrm{R}=0.46 \%$ correct of attempted problems), but the results are still statistically significant $(p=0.00031)$.

In addition to the overall performance on the chemical engineering problem-solving task, we also examined the individual problems to determine

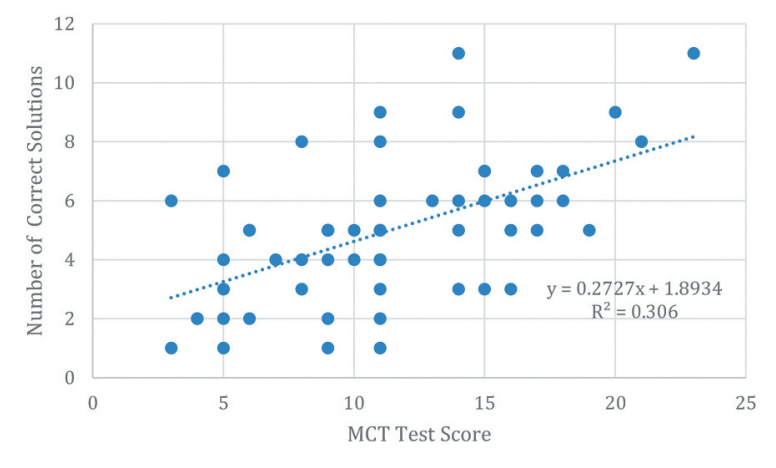

Figure 2. Scatter plot with results from chemical engineering problems.

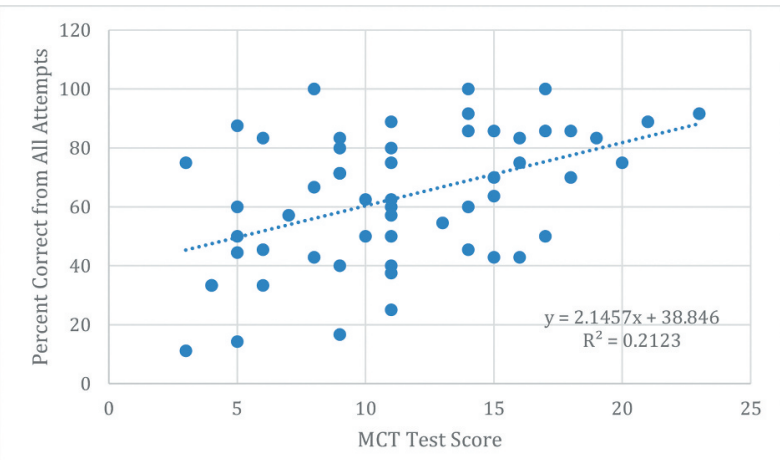

Figure 3. Scatter plot with results from all attempted problems. 
which specific ones were most reliant on spatial skills. In this analysis, the average score on the spatial skills test for the students who answered the problem correctly was computed and compared to the average score for those who got the problem incorrect. When a significant difference existed between spatial scores of students who answered the problem correctly and the spatial scores of students who solved the problem incorrectly, the problem was deemed to be one where spatial skills appear to play a role in their solution. In other words, high spatial skills appeared to give some students an advantage when solving that particular problem. We use the term problem here in its truest sense, i.e. something that has not been seen before by the problem solver, and for which there is no obvious solution path. What is a problem to one student may be a routine question to another as prior knowledge of solving different types of problems varies among individuals. In analysing these data, we did not know how much practice, if any, these students had in solving problems of this nature. However, we were confident they had the requisite procedural knowledge to solve the problems. Table 2 includes the problems where spatial skills appeared to play a role in their solution and Table 3 includes those problems where spatial skills did not appear to play a role in problem solution. It should be noted that one problem (\#8) showed marginal significance $(\mathrm{p}=0.077)$; this problem is included in Table 2. It should also be noted that for this analysis a student was marked incorrect only if they attempted to solve the problem but were unsuccessful. If the problem was not attempted, we had no way of knowing whether this was due to a student not knowing how to solve the problem or if it was due to their running out of time. Thus, the sample size for each problem varies according to the number of students who attempted a given problem.

As can be seen from the data presented in Tables 2 and 3, a little fewer than half of the chosen problems did not seem to have a 'spatial factor.' For these problems $(1,2,9,10$, and 12) the spatial skills of the students who got the problems correct were not different from the spatial skill levels of the students who got them incorrect; recall that problem \#8 showed marginal significance. It should also be noted that problem \#12 had very few respondents - most students did not make it this far in the problem set. So even though it appears that problem \#12 might show a difference in terms of the average MCT score of people who answered it correctly compared to those who did not, the sample size was too low to infer significance.

\section{Discussion}

The problem set used in this study can be divided into mass-balance (Problems 1, 2, 3, 4, 5, 6, 7 and 10) and mass-balance with stoichiometry problems (Problems $8,9,11$ and 12). Some might argue that mass-balance is not inherently spatial in nature and thus not the best candidate subject for this type of research. It should be noted, however, that previous work by Duffy, Sorby, and Bowe 2020 found that it was not the specific topic of the problems but the manner in which the questions were asked that invoked a 'spatial' factor. Word problems displayed a spatial factor; straightforward questions based on the same mathematical principles did not. Mass balance problems were chosen for this study because the mass balance course was a prerequisite for the Thermodynamics course that the students were enroled in - the problems were structured similar to word problems to attempt to elicit the spatial factor. Future research focused on other areas of chemical engineering, such as transport phenomena, could reveal a larger and more consistent spatial factor.

With regard to the; Mayer (1992) framework, these two classes of problems do not necessarily differ in linguistic knowledge but are different in terms of the semantic and schematic knowledge required to solve them. Therefore, each type requires a different representation. Our following analysis of the relationship between spatial ability and problem representation is limited to the eight mass-balance problems. For these problems, the overarching schema is the conservation of mass applied to mixtures of components in two ways: at the component level and for the overall mixture. For four of these problems, 1, 2, 3 and 10, the solution phase requires the procedure of solving two simultaneous equations or a less conventional inverse lever arm rule based on the relative proportions of the separate and combined items. Four problems, 4, 5, 6 and 7, also have this schema but the solution phase is procedurally more straightforward in that it just requires basic arithmetic with a particular order or sequence for calculating each unknown.

Although problems, 1, 2, 3 and 10 are all massbalance in representation and require simultaneous equations in the solution phase, a significant relationship with spatial ability emerged for Problem 3 only. According to the literature, all four problems should have correlated with the spatial test. In fact, Problem 2 had been administered previously to another sample and a significant relationship with spatial ability was found (Duffy et al. 2017). There are two important differences between that study and this. Firstly, the sample size was large in the first study $(\mathrm{n}=1053)$ whereas in this study it is very small for Problem 3. It is possible that if more participants had attempted this problem then it would have been consistent with the others, i.e. no significant difference in spatial ability. Secondly, the sample in the previous study was drawn from first year engineering students whereas 
Table 2. Problems where spatial skills appeared to play a role.

\begin{tabular}{|c|c|c|c|}
\hline Problem & Avg MCT Incorrect Responses & Avg MCT Correct Responses & Significance \\
\hline $\begin{array}{l}\text { 3. One vegetable oil contains } 8 \% \text { saturated fats and a second } \\
\text { oil contains } 26 \% \text { saturated fats. In making a salad dressing } \\
\text { from these two oils how many ounces of the second must } \\
\text { be added to } 10 \text { ounces of the first in order for the dressing } \\
\text { to have } 14 \% \text { saturated fats. }\end{array}$ & $9.5(n=4)$ & $17.44(n=9)$ & $p<0.0001$ \\
\hline $\begin{array}{l}\text { 4. One thousand kilograms per hour of a mixture of } \\
\text { benzene (B) and toluene }(T) \text { containing } 50 \% \text { benzene } \\
\text { by mass is separated by distillation into two fractions. } \\
\text { The mass flow rate of benzene in the top stream is } \\
450 \mathrm{~kg} \mathrm{~B} / \mathrm{h} \text { and that of toluene in the bottom stream is } \\
475 \mathrm{~kg} \mathrm{~T} / \mathrm{h} \text {. The operation is at steady state. Calculate } \\
\text { the unknown component flow rates in the output } \\
\text { streams. }\end{array}$ & $9.3(n=21)$ & $12.5(n=34)$ & $p=0.0169$ \\
\hline $\begin{array}{l}\text { 5. Two methanol-water mixtures are contained in separate } \\
\text { flasks. The first mixture contains } 40.0 \mathrm{wt} \% \text { methanol, and } \\
\text { the second contains } 70.0 \mathrm{wt} \% \text { methanol. If } 200 \mathrm{~g} \text { of the } \\
\text { first mixture is combined with } 150 \mathrm{~g} \text { of the second, } \\
\text { calculate the mass and composition of the product. }\end{array}$ & $4.8(n=5)$ & $11.88(n=52)$ & $p=0.0014$ \\
\hline $\begin{array}{l}\text { 6. Two streams consisting of } 3.0 \mathrm{~kg} / \mathrm{min} \text { of benzene } \\
\text { (B) and } 1.0 \mathrm{~kg} / \mathrm{min} \text { of toluene (T) are well mixed in } \\
\text { a container. The mixed product flows from the } \\
\text { container at a rate of } m(\mathrm{~kg} / \mathrm{min}) \text { and has a } \\
\text { composition of } x(\mathrm{~kg} \mathrm{~B} / \mathrm{kg}) \text {. Determine } m(\mathrm{~kg} / \mathrm{min}) \\
\text { and } x \text {. }\end{array}$ & $7.71(n=7)$ & $11.94(n=47)$ & $p=0.0334$ \\
\hline $\begin{array}{l}\text { 7. A liquid mixture containing } 45.0 \% \text { benzene }(\mathrm{B}) \text { and } \\
55.0 \% \text { toluene }(\mathrm{T}) \text { by mass is fed to a separation } \\
\text { column. A product stream leaving the top of the } \\
\text { column contains } 95.0 \text { mole } \% \mathrm{~B} \text {, and a bottom product } \\
\text { stream contains } 8.0 \% \text { of the benzene fed to the } \\
\text { column. The volumetric flow rate of the feed stream is } \\
2000 \mathrm{~L} / \mathrm{h} \text { and the specific gravity of the feed mixture is } \\
0.872 \text {. Calculate the mass flow rate of the overhead } \\
\text { stream and the mass flow rate and composition (mass } \\
\text { fraction) of the bottom product stream. }\end{array}$ & $11.54(n=22)$ & $15.17(n=12)$ & $p=0.0168$ \\
\hline $\begin{array}{l}\text { 8. If the water-gas shift reaction, } \\
\mathrm{CO}(\mathrm{g})+\mathrm{H} 2 \mathrm{O}(\mathrm{g}) \quad \mathrm{CO} 2(\mathrm{~g})+\mathrm{H} 2(\mathrm{~g}) \\
\text { proceeds to equilibrium at a temperature } \mathrm{T}(\mathrm{K}) \text {, the } \\
\text { mole fractions of the four respective species satisfy the } \\
\text { relation } \\
\text { where } \mathrm{K}(\mathrm{T}) \text { is the reaction equilibrium const. } \mathrm{K}=1 \text { at } \\
\mathrm{T}=1105 \mathrm{~K} \text {. } \\
\text { Suppose the feed to a reactor contains } 1.00 \text { mol of } \mathrm{CO} \text {, } \\
2.00 \text { mol of } \mathrm{H} 2 \mathrm{O} \text {, and no } \mathrm{CO} 2 \text { or } \mathrm{H} 2 \text {, and the reaction } \\
\text { mixture comes to equilibrium at } 1105 \mathrm{~K} \text {. Calculate the } \\
\text { equilibrium composition and the fractional conversion } \\
\text { of the limiting reactant. }\end{array}$ & $11.14(n=22)$ & $15.43(n=6)$ & $p=0.077$ \\
\hline 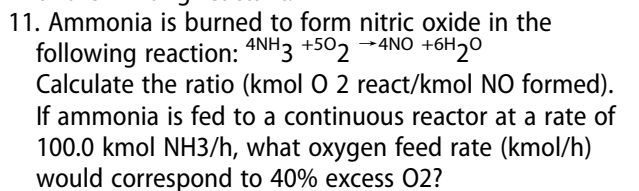 & $8.87(n=8)$ & $13.0(n=24)$ & $p=0.0403$ \\
\hline
\end{tabular}

the participants in this study were in third year of chemical engineering, a programme of study that includes mass-balance analysis as a learning outcome. It is possible these problems were familiar to the sample in the current study and were, therefore, not problems in the true sense but routine questions they have answered many times before. It is argued that spatial ability is most relevant to performance among novices and less relevant to performance in problem solving among experts (Uttal and Cohen 2012). However, the success rate on these problems was not great $-67 \%$ correct on Problem 1, 60\% on Problem 2, $69 \%$ on Problem 3 and 52\% on Problem 10. This suggests a lack of expertise in mass-balance problems for many in this sample yet a correlation with spatial ability is not evident. Further analysis is required to examine the errors made by these students in solving these problems and to determine if they are errors in the representation or solution phases.

Since Problems 4, 5, 6 and 7 are also in the massbalance category they too should follow the trend established by Problems 2, 3 and 10, but they do not - the data for these problems reveals a difference in spatial ability. Problems 5 and 3 illustrate this contradiction well as the representation of each is essentially the same. Where they differ is in the solution phase with Problem 5 requiring the calculation of one unknown from one equation and Problem 3 requiring the solution of two simultaneous equations. However, this difference in the solution phase should not impact on the spatial ability relationship given that spatial ability is only relevant to the representation phase 
Table 3. Problems where spatial skills did not appear to play a role.

\begin{tabular}{|c|c|c|c|}
\hline Problem & Avg MCT Incorrect Responses & Avg MCT Correct Responses & Significance \\
\hline $\begin{array}{l}\text { 1. You have been asked to provide } 150 \mathrm{ml} \text { of hydrochloric } \\
\text { acid at a } 12 \% \text { concentration. In the cabinet you find } \\
\text { one bottle marked } 10 \% \mathrm{HCl}(10 \% \text { hydrochloric acid) } \\
\text { and another bottle marked } 25 \% \mathrm{HCl} \text { ( } 25 \% \text { hydrochloric } \\
\text { acid). How many } \mathrm{ml} \text { of each should you use? }\end{array}$ & $10.42(n=14)$ & $10.11(n=28)$ & NS \\
\hline $\begin{array}{l}\text { 2. How many pounds of M\&Ms that cost } 1.60 \text { USD } \\
\text { per pound must be mixed with } 7 \text { pounds of Smarties } \\
\text { that cost } 2.20 \text { USD per pound to make a mixture of } \\
\text { sweets that costs } 2.00 \text { USD per pound? }\end{array}$ & $9.4(n=17)$ & $10.72(n=25)$ & NS \\
\hline $\begin{array}{l}\text { 9. Given the dehydrogenation of ethane in a steady-state } \\
\text { continuous reactor where the following reaction } \\
{ }^{\mathrm{C}_{2} \mathrm{H}} 6 \rightarrow \mathrm{C}_{2}{ }^{\mathrm{H}} 4^{+\mathrm{H}} 2 \\
{ }^{\circ} \mathrm{ccurs} \text {. If one hundred } \mathrm{kmol} / \mathrm{min} \text { of ethane is fed to the } \\
\text { reactor, and the molar flow rate of } \mathrm{H} 2 \text { in the product } \\
\text { stream is } 40 \mathrm{kmol} / \mathrm{min} \text {, use an atomic balance to calculate } \\
\text { the amounts of } \mathrm{C}^{\mathrm{H}} 6 \text { and } \mathrm{C} \mathrm{C}^{\mathrm{H}} 4 \text { in the product stream. }\end{array}$ & $12.0(n=13)$ & $12.58(\mathrm{n}=19)$ & NS \\
\hline $\begin{array}{l}\text { 10. A paint mixture containing } 25.0 \% \text { of a pigment and } \\
\text { the balance water sells for } 18.00 \text { USD } / \mathrm{kg} \text {, and a mixture } \\
\text { containing } 12.0 \% \text { pigment sells for } 10.00 \text { USD } / \mathrm{kg} \text {. If } \\
\text { a paint retailer produces a blend containing } 17 \% \\
\text { pigment, what should the sales price be in order to } \\
\text { yield a } 10 \% \text { profit? }\end{array}$ & $11.77(n=13)$ & $13.07(n=14)$ & NS \\
\hline $\begin{array}{l}\text { 12. In the Deacon process for the manufacture of chlorine, } \\
\mathrm{HCl} \text { and } \mathrm{O} 2 \text { react to form } \mathrm{Cl} 2 \text { and } \mathrm{H} 2 \mathrm{O} \text {. Sufficient air ( } 21 \\
\text { mole\%, } 79 \% \mathrm{~N} 2 \text { ) is fed to provide } 35 \% \text { excess oxygen and } \\
\text { the fractional conversion of } \mathrm{HCl} \text { is } 85 \% \text {. Calculate the mole } \\
\text { fraction of the product stream components using atomic } \\
\text { species balances. }\end{array}$ & $12.11(n=9)$ & $14.33(n=3)$ & NS \\
\hline
\end{tabular}

(Duffy, Sorby, and Bowe 2020). However, there is an issue with sample size for these problems. Compared with Problems 4 and 7, very few participants were incorrect on Problems 5 and 6 with the majority of the class solving them correctly. The minority who failed to solve these had a very low average spatial ability score. Of the five people who answered problem 5 incorrectly, four of them also answered 6 incorrectly. Table 4 includes additional information for these four students. Recall that there are 25 points possible on the MCT and there were 12 points possible from the Chemical Engineering problem set.

From the data presented in Table 4, it is clear that the four students who got both of the problems incorrect, where the vast majority of their peers answered them correctly, had extremely low visualisation scores compared to their peers. Their MCT scores were more than one standard deviation below the average scores and were close to, or below, chance. Women and international students were also overrepresented in this group. Women comprised $31.7 \%$ of the sample overall, but were $50 \%$ of the group who did poorly on these two 'easy' problems. International students made up only $14.3 \%$ of the overall sample but were $75 \%$ of the group who struggled with these problems even though they had taken a pre-requisite course on mass-balance analysis. In a previous study by Sorby and Veurink (2012) it was found that students from certain countries (i.e., Africa, india, and the Middle East) appear to have weak spatial skills when compared to their American counterparts. These findings could have serious implications in our attempts to diversify our engineering programmes. Given the small sample size, we hesitate to make generalisations based on these findings; further analysis is required.

Cognitively, these participants may be similar to a group labelled as 'non-rotators' by Geiser, Lehmann, and Eid (2006) which failed to show any ability to mentally rotate objects during a test of spatial ability and performed dramatically lower to other groups in the study. Their particularly low spatial visualisation skills may inhibit their ability to develop appropriate mental representations of these problems which prevents them from gaining mastery in solving these problems.

Of the mass-balance problems, the results for Problem 7 are worth some further analysis. Like Problem 4, it revealed a significant difference in spatial ability but the average MCT score of the correct group is much higher. Problems 4 and 7 differ somewhat in representation. While both have the same schema (a two component stream is split into two streams with conservation of mass), Problem 7 is more challenging

Table 4. Detailed data for the four students who answered both Problems 5 and 6 incorrectly.

\begin{tabular}{|c|c|c|c|c|c|}
\hline $\begin{array}{l}\text { Student } \\
\text { Number }\end{array}$ & $\begin{array}{l}\text { MCT } \\
\text { Score }\end{array}$ & $\begin{array}{c}\text { Enrolment } \\
\text { Status }\end{array}$ & Gender & $\begin{array}{l}\text { Number of } \\
\text { Chemical } \\
\text { Engineering } \\
\text { Problems } \\
\text { Answered } \\
\text { Correctly }\end{array}$ & $\begin{array}{c}\text { Number of } \\
\text { Problems } \\
\text { Attempted }\end{array}$ \\
\hline 1 & 5 & International & Male & 4 & 9 \\
\hline 2 & 8 & International & Female & 3 & 7 \\
\hline 3 & 4 & Domestic & Male & 2 & 6 \\
\hline 4 & 3 & International & Female & 1 & 9 \\
\hline
\end{tabular}


at the linguistic level (more assignment statements) and at the semantic level (mole fraction as well as mass fraction). As shown by Duffy, Sorby, and Bowe (2020), when problems have several assignment and/or relational statements, success in representation can be related to spatial ability.

Viewed from a memory model of cognition (Baddeley and Logie 1999), Problem 7 places higher demands on working memory (WM) because it has more assignment statements and requires moving back and forth between mass and mole fractions. Since a greater number of items must be maintained in WM, those with higher WM capacity are less likely to drop or omit one or more of these items and err in problem representation. Tests of spatial visualisation provide a measurement of visuospatial component of WM capacity (Kyttälä and Lehto 2008) and those with high MCT scores are more likely to maintain the large number of items in WM and be successful in problem representation.

The development of mastery can also be viewed in this way. When first encountered in the early years of a chemical engineering programme, the mass-balance problems are novel and WM dominates the process of creating representations. Over time and with practice, representation development becomes routine and is embedded in long term memory so that it is readily available for recall when solving a mass-balance problem. Now, WM is less important so a relationship between problem solving and a measurement of WM, e.g. the MCT becomes insignificant. However, it is possible that those with very low spatial ability/WM fail to embed appropriate representations in long term memory and do not show mastery in this area. It is also possible these students do have the ability to form correct representations but have failed to develop the core competencies required for the solution phase of these problems. In previous work, it was found that when spatial ability is significantly related to success in problem solving, it impacts performance in the representation phase only (Duffy, Sorby, and Bowe 2020). Therefore, a correlation between spatial ability and problem solving implies differences in the way the participants are representing the problems rather than differences in core competencies. However, in future work, it would be very useful to include a test of the procedural knowledge required for solving each problem so the issue of deficiencies in core competencies impacting problem solving performance can be thoroughly addressed.

The results from this project have broad implications for engineering curricula. If spatial skills are important to success in engineering problem-solving, how do we ensure that our students develop these vital skills? One way would be to implement a special course aimed specifically at developing 3-D spatial skills as has been done by Sorby and adopted by engineering programmes in the U. S. Another way may be by 'spatialising' the curriculum throughout so that spatial skills are developed across multiple courses in multiple years. A third way might be by providing additional support for students in places where we know that spatial thinking is required. Based on the results of this study, one area that might be in need of providing extra support for students is in the problem conception area and providing explicit instructions regarding methods for translating 'words' into 'equations.' Regardless of the approach taken, it is important that engineering faculty, who likely have excellent spatial skills themselves, understand that there may be some students in their courses who do not have excellent (or even good) spatial skills. Unfortunately, the students in our programmes with weak spatial skills are more likely to be women, meaning that supportive actions by faculty could have an impact on our ability to retain women in engineering.

\section{Conclusions}

Of the eight mass-balance problems in the set, seven either didn't reveal a difference in spatial ability or if they did, the difference was due to the presence in the sample of a minority of participants with very low spatial ability. This suggests that a majority of this sample has achieved mastery in this area and these problems are not truly problems in the sense that a readily accessible representation is available in long term memory. The minority of low spatial ability participants consistently failed to demonstrate appropriate representations of these problems. It appears they do not have a readily available representation that is appropriate to these problems and have yet to develop mastery in this area.

One of the problems (\#7) revealed a notable difference in spatial ability. Comparing its representation to the other problems we find that it was similar in schematic knowledge but presented greater challenges in linguistic and semantic knowledge. Those who were successful in solving this problem had a high average spatial ability score. This suggests that even though they may be correct in representation at the schematic level, students with lower spatial ability may be challenged by problems that contain a large number of linguistic and semantic items. WM overload can be reduced by externalising the different representation components, e.g. using a sketch to create an external visualisation and relational statements and other information has been correctly identified and translated.

In future work, it would be interesting to examine the role of $\mathrm{WM}$, in particular visuospatial WM, in engineering problem solving in greater detail by using a wider range of WM instruments. Problems could be chosen that increase the number and type 
of representation items to test the hypothesis that WM plays a key role in problem solving and that spatial ability is a key factor in this relationship. This work could be extended to other engineering disciplines so the process of developing mastery could be explored across a range of areas.

\section{Acknowledgments}

This material is based upon work supported by the National Science Foundation in the U. S. under grants number DRL1535307 (PI: Perez) and DRL-1818758 (PI: Sorby). Any opinions, findings, and conclusions or recommendations expressed in this material are those of the authors and do not necessarily reflect the views of the National Science Foundation.

\section{Disclosure statement}

No potential conflict of interest was reported by the authors.

\section{Funding}

This work was supported by the National Science Foundation [DRL-1818758 and DRL-1535307].

\section{References}

ABET. 2016. "Criteria for Accrediting Engineering Programs (Effective for Evaluations during the 2017-2018 Accreditation Cycle)." Accreditation Board for Engineering and Technology, Engineering Accreditation Commission. http://www.abet.org/accredi tation/accreditation-criteria/criteria-for-accreditingengineering-programs-2017-2018/

Baddeley, A. D., and R. H. Logie. 1999. "Working Memory: The Multiple-component Model." In Models of Working Memory: Mechanisms of Active Maintenance and Executive Control, edited by A. Miyake and P. Shah, 1999-02490-001; 28-61. Cambridge, UK: Cambridge University Press. doi:10.1017/CBO9781139174909.005.

Baddeley, A. D. 2012. "Working Memory: Theories, Models, and Controversies." Annual Review of Psychology 63 (1): 1-29. doi:10.1146/annurev-psych-120710-100422.

Boonen, A. J. H., F. van Wesel, J. Jolles, and M. van der Schoot. 2014. "The Role of Visual Representation Type, Spatial Ability, and Reading Comprehension in Word Problem Solving: An Item-level Analysis in Elementary School Children." International Journal of Educational Research 68: 15-26. doi:10.1016/j.ijer.2014.08.001.

Carroll, J. B. 1993. Human Cognitive Abilities: A Survey of Factor-analytic Studies. Cambridge, UK: Cambridge University Press.

Carroll, J. B. 1996. "A Three-stratum Theory of Intelligence: Spearman's Contribution.” In Human Abilities: Their Nature and Measurement, edited by I. Dennis and P. Tapsfield, 1-17. https://books.google.com/books?hl= en\&id=JQX-PIF6EgYC\&oi=fnd\&pg=PA1\&dq=ThreeStratum + Theory+of + + in telligence \&ots = pNLaysHXX\&sig=fm0uwps6DsjFEyTcAJsDfFPNoPQ

Casey, M. B., E. Pezaris, and R. L. Nuttall. 1992. Spatial ability as a predictor of math achievement: The importance of sex and handedness patterns. Neuropsychologia
30 (1): 35-45. https://doi.org/10.1016/0028-3932(92) 90012-B

CEEB. 1939. CEEB Special Aptitude Test in Spatial Relations. College Entrance Examination Board.

Clement, J. J. 1982. "Algebra Word Problem Solutions: Thought Processes Underlying a Common Misconception." Journal for Research in Mathematics Education 13 (1): 16-30. doi:10.2307/748434.

Deno, J. A. 1995. The relationship of previous experiences to spatial visualization ability. Engineering Design Graphics Journal 59 (3): 5-17.

Duffy, G., S. A. Sorby, A. Mack, and B. Bowe 2017, June 26. "Performance by Gender on University Placement Tests in Mathematics and Spatial Skills." In ASEE Annual Conference 2017. Columbus Ohio. https://peer.asee.org/ 28737.pdf

Duffy, G., S. A. Sorby, and B. Bowe. 2020. "Spatial Ability Is a Key Cognitive Factor in the Representation of Word Problems in Mathematics among Engineering Students." Journal of Engineering Education:1-19, DOI: 10.1002/jee.20349

Eliot, L. 2009. Pink brain, blue brain: how small differences grow into troublesome gaps-and what we can do about it. Houghton Mifflin Harcourt, Boston, p. 420

Farrell, S., A. Behan, G. Duffy, R. Harding, R. Howard, A. Mac Raighne, E. Nevin, and B. Bowe 2015. "A Profile of the Spatial Visualisation Abilities of First Year Engineering and Science Students." http://arrow.dit.ie/ engschcivcon $/ 90 /$ ? utm_source=arrow.dit.ie $\%$ 2Fengschcivcon\%2F90\&utm_medium $=$ PDF\&utm_cam paign $=$ PDFCoverPages

Felder, R. M., and R. W. Rousseau. 2000. Elementary Principles of Chemical Processes. 3rd international ed. New York, Chichester: John Wiley.

Ganley, C. M., and M. Vasilyeva. 2011. Sex differences in the relation between math performance, spatial skills, and attitudes. Journal of Applied Developmental Psychology 32 (4): 235-242.

Geiser, C., W. Lehmann, and M. Eid. 2008. A note on sex differences in mental rotation in different age groups. Intelligence 36 (6): 556-563. https://doi.org/10.1016/j. intell.2007.12.003

Geiser, C., W. Lehmann, and M. Eid. 2006. "Separating "Rotators" from "Nonrotators" in the Mental Rotations Test: A Multigroup Latent Class Analysis." Multivariate Behavioral Research 41 (3): 261-293. psyh. doi:10.1207/ s15327906mbr4103_2.

Guay, R. 1976. Purdue Spatial visualisation Test. West Lafayette, Indiana, USA: Purdue University.

Hegarty, M., and M. Kozhevnikov. 1999. "Types of Visualspatial Representations and Mathematical Problem Solving." Journal of Educational Psychology 91 (4): 684-689. doi:10.1037/0022-0663.91.4.684.

Hier, D. B. and W. F. Crowley. Jr. 1982. Spatial ability in androgen-deficient men. New England Journal of Medicine 306: 1202-1205.

Isaacson, W. 2007. Einstein: His Life and Universe. London, UK: Simon \& Schuster.

Johnson, W., and T. J. Bouchard Jr. 2005. “The Structure of Human Intelligence: It Is Verbal, Perceptual, and Image Rotation (VPR), Not Fluid and Crystallized." Intelligence 33 (4): 393-416. psyh. doi:10.1016/j. intell.2004.12.002.

Kali, Y., and N. Orion. 1996. "Spatial Abilities of High-school Students in the Perception of Geologic Structures." Journal of Research in Science Teaching 33 (4): 369-391. doi:10.1002/(SICI)1098-2736(199604) 33:4<369::AID-TEA2>3.0.CO;2-Q. 
Kozhevnikov, M., M. Hegarty, and R. Mayer. 2002. "Spatial Abilities in Problem Solving in Kinematics." In Diagrammatic Representation and Reasoning, edited by M. Anderson, B. Meyer, and P. Olivier, 155-171. London, UK: Springer. doi:10.1007/978-1-4471-0109-3_9.

Kozhevnikov, M., M. A. Motes, and M. Hegarty. 2007. "Spatial visualization in Physics Problem Solving." Cognitive Science 31 (4): 549-579. a9h. doi:10.1080/ 15326900701399897.

Kyttälä, M., and J. E. Lehto. 2008. "Some Factors Underlying Mathematical Performance: The Role of Visuospatial Working Memory and Non-verbal Intelligence." European Journal of Psychology of Education - EJPE (Instituto Superior de Psicologia Aplicada) 23 (1): 77-94.

Linn, M. C., and A. C. Petersen. 1985. "Emergence and Characterization of Sex Differences in Spatial Ability: A Meta-analysis." Child Development 56 (6): 1479-1498. doi:10.2307/1130467.

Lohman, D. F. 1996. "Spatial Ability and G." In Human Abilities: Their Nature and Measurement, edited by I. Dennis and P. Tapsfield, 1996-98789-006; 97-116. Hillsdale, NJ: Lawrence Erlbaum Associates.

Mayer, R. E. 1992. Thinking, Problem Solving, Cognition. New York, NY: W.H. Freeman.

McGee, M. G. 1979. "Human Spatial Abilities: Psychometric Studies and Environmental, Genetic, Hormonal, and Neurological Influences.” Psychological Bulletin 86 (5): 889-918. doi:10.1037/0033-2909.86.5.889.

Mix, K. S., and Y.-L. Cheng. 2012. "Chapter 6 - the Relation between Space and Math: Developmental and Educational Implications." In Advances in Child Development and Behavior, edited by J. B. Benson, Vol. 42; 197-243. Greenwich, CT: JAI. doi:10.1016/ B978-0-12-394388-0.00006-X.

Schneider, W. J., and K. S. McGrew. 2012. "The CattellHorn-Carroll Model of Intelligence." In Contemporary Intellectual Assessment: Theories, Tests, and Issues., edited by D. P. Flanagan and P. L. Harrison, 2012-09043-004; 99-144. 3rd ed. New York, NY: Guilford Press.

Silverman, I., J. Choi, A. MacKewn, M. Fisher, J. Moro, and E. Olshansky. 2000. Evolved mechanisms underlying wayfinding: Further studies on the hunter-gatherer theory of spatial sex differences. Evolution and Human Behavior 21: 201-213.

Sorby, S., C. Leopold, and R. Gorska. 1999. Cross-Cultural Comparisons of Gender Differences in the Spatial Skills of Engineering Students. Journal of Women and Minorities in Science and Engineering 5 (3): 279-291.

Sorby, S. A. 2001. "Improving the Spatial Skills of Engineering Students: Impact on Graphics Performance and Retention." Engineering Design Graphics Journal 65 (3): 31-36.

Sorby, S. A. 2016. Developing Spatial Thinking. Higher Education Services, Houghton, MI, USA, p. 225
Sorby, S. A., B. Casey, N. Veurink, and A. Dulaney. 2013. "The Role of Spatial Training in Improving Spatial and Calculus Performance in Engineering Students." Learning and Individual Differences 26: 20-29. a9h. doi:10.1016/j.lindif.2013.03.010.

Sorby, S. A., N. Veurink, and S. Streiner. 2018. Does Spatial Skills Instruction Improve STEM Outcomes? The Answer is 'Yes'. Journal of Learning and Individual Differences, 67: 209222.

Sorby, S. A., and N. L. Veurink. 2012, June. Spatial Skills Among Minority and International Engineering Students. Proceedings of the Annual Conference of the American Society for Engineering Education, San Antonio, TX.

Tarampi, M. R., N. Heydari, and M. Hegarty. 2016. A Tale of Two Types of Perspective Taking: Sex Differences in Spatial Ability. Psychological Science 27 (11): 1507-1516. https://doi.org/10.1177/0956797616667459

Uttal, D. H., and C. A. Cohen. 2012. Spatial Thinking and STEM Education. When, Why, and How? Vol. 57. Scopus. http://www.scopus.com/inward/record.url? eid=2-s2. $0-84860615431 \&$ partner I D $=40 \&$ m d $5=$ 9e7bafd47ed3bb637fcef4311e09dfd7

Uttal, D. H., N. G. Meadow, E. Tipton, L. L. Hand, A. R. Alden, C. Warren, and N. S. Newcombe. 2013. The malleability of spatial skills: A meta-analysis of training studies. Psychological Bulletin 139 (2): 352-402. doi:10.1037/a0028446

Veurink, N. and S. Sorby. 2014. "Development of Spatial Visulization Skills through Engineering Curricula," Proceedings of the 69th Midyear Conference of the Engineering Design Graphics Division of ASEE, Normal, IL, October 2014

Veurink, N., and S. A. Sorby. 2011. "Raising the Bar? A Longitudinal Study to Determine which Students Would Benefit Most from Spatial Skills Training," Proceedings of the 2011 Annual Conference of the American Society for Engineering Education, Vancouver, Canada, June 2011

Voyer, D., S. Voyer, and M. Bryden. 1995. Magnitude of sex differences in spatial abilities: A meta-analysis and consideration of critical variables. Psychological Bulletin 117 (2): $250-270$.

Wai, J., D. Lubinski, and C. P. Benbow. 2009. "Spatial Ability for STEM Domains: Aligning over 50 Years of Cumulative Psychological Knowledge Solidifies Its Importance." Journal of Educational Psychology 101 (4): 817. doi:10.1037/a0016127.

Wu, H.-K., and P. Shah. 2004. "Exploring Visuospatial Thinking in Chemistry Learning." Science Education 88 (3): 465-492. doi:10.1002/sce.10126.

Yoon, S. Y. 2011. Psychometric Properties of the Revised Purdue Spatial visualization Tests: visualization of Rotations (The Revised PSVT-R). ERIC. http://eric.ed. gov/?id=ED534824 